\title{
La crónica de sucesos. Evolución del género en el world wide web
}

institucional.us.es/ambitos/

Alberto Albacete Carreñojefedepolicia@ayto-valdemoro.org

María Pilar Antolínez Merchán

Universidad CJC

pantolinez@ucjc.edu

\author{
María Cristina Cañamero Alvarado \\ Universidad CJC \\ ccanamero@ucjc.edu
}

\section{Resumen}

Estudio y análisis sobre la evolución del género periodístico, dentro de la era digital mediante con casos que han provocado discusión social sobre la aplicación de la justicia.El objetivo será poner de manifiesto las relaciones que se pueden establecer entre diferentes tipos de textos y su contenido, tratando de mostrar la repercusión y calado social que tendrán, con la llegada del World Wide Web, la globalización de la información hace que las noticias tengan repercusión a nivel internacional. La propia crónica de sucesos, va evolucionando según la sociedad, y evoluciona tanto en su forma como en su fondo.

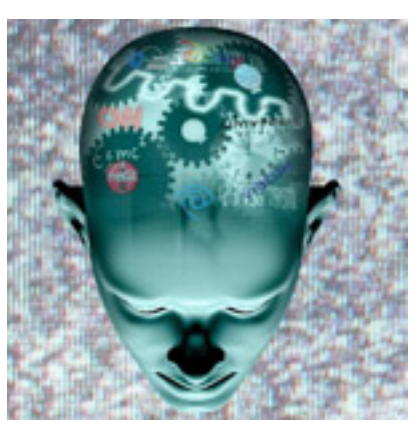

\section{Palabras clave}

Periodismo, sucesos, crónica, crimen, justicia.

\begin{abstract}
Study and analysis on the evolution of journalistic genre, in the digital age through with cases that have caused social discussion on the implementation of justice. The aim will be to highlight the relationships that can be established between different types of texts and their content, trying to show the impact and social significance that have, with the advent of the World Wide Web, the globalization of information have made the news international repercussions. The own chronicle of events, as society evolves, and evolves both in form and in substance.
\end{abstract}

\section{Keywords}

Journalism, events, chronic, crime, justice.

\section{INTRODUCCIÓN}

La investigación en ciencias sociales se convierte en una tarea compleja, más cuando se intentan poner en relación textos que están separados no sólo por el tiempo, y por la tipología de los hechos que narran, no solo analizándolo desde el punto de vista periodístico, también teniendo en cuenta su repercusión social y su pervivencia dentro de nuestros referentes mediáticos.

La prensa escrita, al igual que en la antigüedad lo fueron las crónicas, se convierte en un reflejo de la sociedad. Por lo tanto su utilización como fuente de información se convierte en un referente equiparable a otras fuentes históricas. Sobre todo si tenemos en cuenta que en el siglo XX la "revolución informativa" que había comenzado a finales del XIX, hace que la prensa sea denominada el "cuarto poder", los autores ingleses hablan de los Mass Comunication (Comunicación de Masas), apostillando que un hecho se convertirá necesariamente en información cuando la población la entienda, la asimile y la convierta en un hecho social. En los albores del 
siglo XXI se producirá un proceso similar, cuando internet se eleve al medio de comunicación por excelencia, no sólo por la rapidez en la forma de comunicar, sino por su versatilidad, ya que permite ver, buscar,..., en todos los medios de comunicación pudiendo hacer una lectura crítica de las noticias, incluso de la crónica de sucesos, como se planteará en los últimos casos de estudio.

Según afirma Montse Quesada, el periodismo de sucesos es anterior a la aparición de las especializaciones periodísticas, remontándose a los orígenes de la prensa escrita, puesto que desde las primeras manifestaciones escritas la humanidad ha tenido interés por conocer todo tipo de sucesos, interés que no ha disminuido con el tiempo, al contrario ha ido en aumento, al igual que han crecido y evolucionado los medios de comunicación (Quesada, 2007).

La crónica de sucesos no es solo una disciplina más dentro de las materias estudiadas por los periodistas, en ella no solo se deben exponer los hechos de manera clara y estructurada, también se conjugan factores determinantes que atañen a otras áreas de conocimiento como son el Derecho o la Criminología, al tener que incluir datos y vocabulario especializado, conocer todo lo que tiene que ver con el ámbito permitirá una mayor veracidad a la hora de transmitir la información. Algo que viene sucediendo en las últimas décadas o en publicaciones especializadas como El Caso.

No solo estas disciplinas tienen cabida en la redacción y difusión de una noticia de sucesos, la Sociología, la Psicología,..., juegan también su papel con mayor o menor protagonismo, al ser elementos que ayudan a estudiar, medir y determinar la difusión y calado de una noticia, o de su protagonista en un colectivo social mediante la Opinión Pública.

La crónica de sucesos es un reflejo de la sociedad, igual que otros géneros periodísticos, pero en el caso que nos ocupa veremos cómo se va adaptando a los medios de comunicación con los que va contando para su difusión, se va erigiendo en un género imprescindible para la información diaria, saltando de las revistas especializadas o de las páginas de los periódicos o de las páginas de periódicos denominados como tal, a ser una portada o un trendictopic con la llegada del World Wide Web. La propia crónica de sucesos, independientemente de su forma va evolucionando según la sociedad, y evoluciona tanto paralelamente en su forma como en su fondo.

\section{OBJETIVOS}

El análisis se realiza en torno a ejemplos de textos que componen el estudio de caso, siendo en su temática y forma variados, porque cada uno contiene unos hechos, acontecimientos y personajes. Sin embargo, tienen un trasfondo común, en todas ellas se narran hecho de interés social, que configuran la construcción de la crónica, o de la historia reciente de la crónica de sucesos de nuestro país. Todos ellos comparten el interés y la necesidad de mostrar de una manera referencial los personajes y las noticias que conmueven los cimientos de la sociedad, impregnado con la imagen de las personas retratada no sólo al público que las lee en ese momento, sino también a las generaciones venideras. Puesto que los trabajos que se presentan como objeto de análisis contienen referencias que son, incluso fuera del contexto en el que se desarrollaron, ya que han sobrevivido al paso del tiempo, en algunos casos por su reaparición en los medios de comunicación, en otros por convertirse en referencias populares o audiovisuales.

Las líneas maestras se centran en el estudio de las relaciones que se pueden establecer en torno a diferentes tipos de textos y su contenido, tratando de mostrar la repercusión y calado social que tendrán, no sólo hechos acontecidos dentro de las fronteras de España, sino que con la llegada del World Wide Web, la globalización de la información hace que noticias como el juicio por el Caso Marta del Castillo o Wikileaks, tengan repercusión y seguimiento a nivel internacional, deben ser vistos como ejemplos incluyentes, no excluyentes, de otros muchos acontecimientos importantes mediáticamente a lo largo del siglo que tratamos.

Analizar el modo en que el discurso del género crónica construye diferentes miradas acerca del crimen, del criminal, de la justicia, de las fuerzas de seguridad, y de los diferentes participantes de los sucesos que abordan, atendiendo a su relación con el contexto histórico en cada momento.

Realizar un análisis de cómo las nuevas tecnologías influyen en el relato de crónicas de sucesos y los 
problemas que se derivan de ello a nivel de secreto sumarial, y secreto profesional de los Cuerpos de Seguridad Pública, así como de aumento de las posibilidades delictivas en Internet.

Los discursos de la crónica de sucesos ponen de manifiesto los sistemas de relaciones sociales imperantes en un momento histórico dado.

A la hora de comprender cómo la crónica de sucesos construye sus discursos y cómo estos interactúan con su contexto de producción, es relevante comprender dos aspectos:

- En cuanto a forma: Por un lado, su vinculación con los géneros interpretativos del periodismo que le acercan a la literatura le hace poseer una mayor libertad para tratar temas de actualidad, generan empatía en el lector e introducen una visión mediatizada por la mirada profesional sobre hechos de interés. A su vez, la permeabilidad que fomentan las nuevas tecnologías influye decisivamente en la investigación de hechos delictivos, tanto a la hora de adquirir información para denunciarlos como a la hora de abrir nuevas puertas a la actividad delictiva. Por esto último asistimos actualmente tanto a un momento de transformación del periodismo como del derecho mismo.

- En cuanto a contenido: Por el otro, los relatos que difunde, caracterizados por hechos delictivos y criminales, tanto sociales como empresariales y políticos, logran difundir representaciones sobre el crimen, la justicia, la seguridad, o el orden público enfatizando en aquellos aspectos que sean útiles a los fines discursivos.

\section{EL DELITO EN EL DISCURSO DE LOS MEDIOS}

"Los periodistas, a diferencia de los detectives, no se preocupan por descifrar el delito; su misión es contarlo" (Rey, www.library.fes.de, 2000)

Ante la proliferación en los medios de comunicación masiva de la representación del crimen en sus versiones más aberrantes, lo cual ya se ha vuelto parte de la agenda informativa, cabe preguntarse sobre el impacto social que genera. El público masivo demanda este tipo de noticias, de las cuales se ha vuelto acérrimo consumidor, pero como contracara emerge la cuestión de su impacto, que puede verse por ejemplo en el incremento de visiones negativas sobre la realidad o del temor generalizado, aspectos que pueden conllevar una interpretación sesgada e incluso subyugante del entorno (Barata, 1996).

Si se reconoce el poder de los medios de comunicación de masas desde su nacimiento y consolidación hasta su enorme expansión actual, es necesario prestar atención al fenómeno de la representación del delito y su impacto social. El control sobre los discursos masivos y su aprovechamiento para generar opinión pública siempre ha sido un objetivo de los grupos de poder. Pero ¿qué ocurre con los discursos masivos en un momento como el actual, en que el ciudadano re-elabora y propone sus propios contenidos sobre los hechos de actualidad y tiene la posibilidad de difundirlos a millones de personas en todo el mundo por la Red? Podría hablarse en cierto modo de un poder social emergente constituido en el tejido social que posibilita Internet.

También emerge a través de estos discursos una percepción sobre la justicia, su accionar, su eficacia o ineficacia, su capacidad de respuesta ante hechos de reciente cuño como la existencia de hackers o de redes delictivas.

El hacer público un hecho criminal y su castigo significaba antaño una legitimación, a través de un ritual, del poder del soberano (Foucault, 1988), pero también podía generar cierta fascinación por el delincuente, prueba de lo cual es la fama que han tomado ciertos criminales que han trascendido a lo largo de la historia.

Desde los estudios de la psicología social se ha concluido que los medios masivos de comunicación son actualmente los principales constructores de las percepciones de miedo e inseguridad en la población. Pareciera que las claves de este tratamiento son las mismas que en el castigo ejemplar del que hablara Foucault: dramatización- para generar impacto en el público- y discurso del orden.

La condena de la violencia se presenta a los medios periodísticos como uno de las principales atractivos, ocupando vastos titulares. 
La dramatización de la violencia funcionaría por un lado como la ejecución pública en el cadalso de siglos atrás, solo que en el discurso de los medios masivos toma un cariz de simulacro y aporta una influencia significativa en la configuración de representaciones sobre la justicia, la injusticia el crimen, la seguridad o inseguridad, etc.

El hecho problemático es la ausencia de profundidad y reflexión en el tratamiento periodístico de delitos graves. Los medios cumplen la función de señalar los sectores sociales conflictivos, pero sin embargo frecuentemente no otorgan una visión crítica de estos hechos. En otras palabras, los medios encienden las alarmas ciudadanas, tal es así que funcionan como indicadores de peligros que atentan sobre posiciones de valor al interior de la comunidad (Barata, 1996).

No se puede decir que los medios favorezcan el desorden social, pero sí que amplíen las barreras de tolerancia sobre el mismo y lo conviertan en objeto de consumo. Esto implica un tratamiento superficial de los hechos delictivos, que, por otro lado, rara vez provienen de fuentes directas-la presencia del cronista in situ es más una excepción que una regla en el periodismo actual- sino más bien de otros grupos sociales implicados, por ejemplo las fuerzas policiales (Barata, 1996).

\section{LA CRÓNICA DE SUCESOS EN LA ERA DEL DELITO INFORMÁTICO}

Si de problemáticas asociadas a la globalización del uso de Internet como medio comunicacional se trata, no podemos dejar de mencionar el denominado "cibercrimen", o delito informático. La acelerada carrera tecnológica propia de la sociedad de la información genera inevitablemente vacíos jurídicos y nuevos problemas para el campo del derecho penal (Landa Durán, 2007).

El código penal no incluye aún una definición precisa, por esto es complejo el tratamiento de los delitos informáticos y los especialistas en la materia utilizan de manera indistinta diferentes denominaciones.

Téllez Valdés (2003, pp. 105), señala las siguientes características para los delitos informáticos:

- Representan acciones de oportunidad, en tanto el criminal saca provecho de las posibilidades que brindan las tecnologías de la información inmersas en un sistema globalizado

- Generalmente implican pérdidas económicas significativas.

- Pueden ser consumadas en un marco de ventajas tanto espaciales como temporales. Algunos delitos informáticos son llevados a cabo en pocos segundos y sin ninguna presencia física.

- La ausencia de regulación en materia de delitos informáticos provoca que muchos casos queden impunes y las denuncias sean escasas.

- Son frecuentes en ámbito militar, debido a la formación de sus miembros y la cercanía a información confidencial, por ejemplo.

- Por estas características presentan dificultades para encontrar evidencias.

- Actualmente algunos delitos informáticos se encuentran aún catalogados como ilícitos impunes de forma explícita ante la ley, sin bien ya se están introduciendo modificaciones por parte del legislador creando tipos delincuenciales relacionados con este tipo de acciones punibles.

Un caso ejemplificador es el ya citado conflicto de Wikileaks. Al respecto, tampoco el periodista tiene una posición clara sobre este tipo de sucesos. ¿Qué ocurre con los criterios de confidencialidad de la información, o bien de verdad, incluidos en la deontología periodística, ante un caso como el de Wikileaks? Algunas voces se han alzado a favor de las acciones de difusión propuestas desde esta plataforma, desde criterios como el de libertad de expresión. Sin embargo otros sectores se preguntan. ¿Es Wikileaks un caso de delito informático? ¿Qué papel cumple la ética en el panorama comunicacional actual? En este como en los otros casos escogidos para la Etapa III del presente trabajo, encontramos una multiplicidad de preguntas y pocas respuestas, así como una permanente confrontación entre dos campos del saber: el de la comunicación y el del derecho. 


\section{EL IMPACTO DE LA CRÓNICA DE SUCESOS EN LA VIDA SOCIAL}

Dentro de los estudios que planteamos, los estudios que abarcan los efectos que tienen los medios de comunicación se erigen como referentes indispensables, así hablaríamos de (Herrero, 2009):

- Teoría sobre la sociedad de masas, donde las Teorías de la Comunicación y de la Información juegan su papel.

\section{- La función de la Sociedad: la Sociología}

- Psicología, para estudiar no sólo los comportamientos sociales, sino las variaciones que la implantación de dichos comportamientos producen en el individuo.

No así su necesidad de conocer lo que sucede a su alrededor, en cuyo caso el medio para no aislarse es la Información, por lo que se establece la vinculación entre el Emisor-Medio y el Receptor-Individuo.

El uso de la violencia en los medios de comunicación siempre fue un recurso de atracción de interés. Su efectividad se basa en el impacto sobre la sensibilidad, que produce una atención alarmada sobre algo. El problema es que los medios, al recurrir a este sistema, necesitan impactar la sensibilidad cada vez más para producir el mismo interés o atención.

Así hoy nos parecen inocentes las fotografías de crímenes mafiosos de principios de siglo, o los relatos truculentos de El Caso en los años 50. Para impactar la sensibilidad, hoy los medios tiene que hacer algo realmente violento y perverso (Vico, 2006).

Un efecto temible de este proceso es lo que se llama la normalización de la violencia en nuestra sociedad. Dado que vivimos un bombardeo constante de violencia activa y pasiva, psicológica y física, para los espectadores la violencia es algo natural y cotidiano. El visionado constante de violencia, conduce a una percepción muy negativa del entorno que vivimos, exagerando el aspecto violento y desaprensivo de la sociedad, y creando miedo, lo cual redunda también en reacciones agresivas, aunque sólo sean ideológicas, entro ese mundo distorsionado por la violencia mediática.

Criterios eran transformados en técnicas, concretas, sobre todo cuando el mensaje que se lanza es asimilado de manera casi inmediata por el público, bien por una situación de empatía, o como en el caso que nos ocupa por el interés que la crónica negra o de sucesos ha levantado en las colectividades (Gutiérrez Espada, 1982, pág. 59)

1/ Simplificación: en vez de una exposición larga y razonada de los hechos, titulares o slogans cortos y claros.

2/ Exageración: manipular hábilmente las noticias importantes, citar fuera de su contexto o resalta lo que es favorable.

3/ Reiteración: se prescribe el mantenimiento del mismo fondo presentado bajo diversas formas. Luego variaba el ritmo que se presentaba, de esta manera se mantiene al público en una expectación constante.

4/ Contagio: mediante manifestaciones masivas, se produce una presión inevitable del grupo en la opinión del individuo, que suponía a través del contagio, un reforzamiento del mensaje transmitido.

5/ Transferencia: Para que un mensaje tenga arraigo en el público, debe ser cercano y conocido, utilizando las creencias preexistentes.

En la construcción del imaginario social incurso en una sociedad, son diferentes las variables que confluyen en su formación, cuando hablamos como en el caso que nos ocupa de la crónica de sucesos y por tanto de crímenes y criminales, los Medios de Comunicación juegan un papel fundamental.

La Comunicación, pasa en los dos últimos siglos se der un mero modo de vida o de transmisión de ideas a ser fuente de información para las ciencias sociales, por su relación con poderes políticos, económicos, sociales,..., siendo no solo un modo donde volcar información, sino también un mecanismo ideal de aculturación, convierten 
a un hecho periodístico en un hecho social.

La era de internet, sea la que se escapa a las primeras afirmaciones vertida en el presente epígrafe, puesto que la rapidez e inmediatez del Medio permite conocer en poco tiempo la noticia desde distintas fuentes con todo lujo de detalle, si bien es cierto que su importancia en la conformación del impacto social frente a un hecho, póngase por ejemplo el caso "Marta del Castillo", es muy valioso, puesto que en redes sociales como Twitter, en sólo unas horas se convirtió en hashtag (1) mundial, no sólo cuando desapareció la joven, sino en todo su proceso posterior, incluidos estos días en los que se desarrolla el proceso judicial y parte de la investigación sigue abierta. La elección de los casos, así como el corte temporal, los medios citados, obedece a una motivación práctica y metodológica, hacer una separación por épocas ateniéndonos a la evolución técnica de los medios de comunicación. Comenzando con el florecimiento de la prensa "amarillista" en España en un primer momento, por la aparición de prensa especializada en sucesos y secciones en prensa generalista, hasta como hemos citado en el párrafo anterior la globalización de la información gracias a la irrupción de internet.

\section{METODOLOGÍA}

La metodología aplicada será cualitativa, distintas formas en un mismo medio por lo tanto, la utilización de una plantilla cerrada de análisis, constreñiría los resultados de una manera que no permitiría realizar un análisis evolutivo de las características comunes que van apareciendo en el género periodístico planteado en el estudio de caso. La investigación social busca vertientes que estudien y manejen los datos y casos de estudio de una manera cualitativa, pero dándole el enfoque y el rigor imprescindible para la obtención de conclusiones válidas. En este caso concreto, la crónica de sucesos, se deben de tener en cuenta una serie de variables, como las conductas, las opiniones, las construcciones sociales, $\ldots .$.

Uno de los puntos restrictivos que se plantean en la presente tesis de doctorado, es la selección de los casos y crónicas que aquí se analizan, la muestra se compondrá de un conjunto de hechos que por su repercusión han tenido una pervivencia en el tiempo, esta premisa que puede parecer una limitación en un primer momento, es lo que invita a la realización de la investigación, la búsqueda de la evolución en la crónica de sucesos adaptándose a los tiempos, a los medios y al público, sin perder su esencia periodística.

Las características principales de la metodología aplicada para el estudio cualitativo serían:

- Captación de datos, al tratarse de una investigación encaminada a la validación de la hipótesis planteada, se ha realizado una búsqueda sistemática de los casos que han quedado en la memoria colectiva, los que han generado un especial interés en los receptores, bien por su aparición en los medios, bien por su repercusión social.

- Análisis del discurso, la moralidad implícita y su repercusión, analizando portadas, titulares, imágenes reales o no que ilustran el texto, será pues nuestro objetivo de análisis desde su dimensión de influencia en el receptor como individuo, teniendo en cuenta que la comunicación de masas es pública.

Los datos cualitativos son los más difíciles de manejar si queremos aplicar una estadística, no siendo ese nuestro objetivo, si debemos buscar un instrumento, más que de medición, de análisis comparativo de los resultados, partiendo de las preguntas de investigación se estudiaran los ejemplos propuestos valorando, la forma y el contenido de los mismos:

- Lenguaje escrito, dependiendo del soporte

- Análisis y observación de los mismos

- Sesgo temporal

- Consecuencia social: corto, medio y largo plazo

La idea de investigación, que pretende dar respuesta a los objetivos que se planteaban: "los discursos de la crónica de sucesos ponen de manifiesto los sistemas de relaciones sociales imperantes en un momento histórico dado" 
- Lenguaje escrito, dependiendo del soporte, la evolución y actualización lingüística, se han mostrado desde los inicios de la prensa amarillista evolucionando hasta llegar a la democratización del verbo en la última etapa tratada y la gran expansión social y mediática del World Wide Web.

- Análisis del discurso, su repercusión, analizando portadas, titulares, imágenes reales, o no, que ilustran el texto, como son casos de diferente procedencia y la aplicación de una ficha cerrada de análisis no daría unos resultados analizables, se incluyen en subcategorías de análisis aplicables al texto según su condición.

- Sesgo temporal, la influencia estatal que puedan condicionar las manifestaciones periodísticas, inclusive en las formas de expresión. Analizándolos desde el punto de vista simbólico y de la moralidad subyacente.

- Consecuencia social: corto, medio y largo plazo. Casos en los que la repercusión en foros sociales ha supuesto un revulsivo para los lectores, puesto que en todos ellos y ajustados a su contexto histórico, han sido protagonistas de la vida social del momento, no sólo en la prensa si no que fueron, o son, comentados en todos los estratos sociales.

- Representación intrínseca de la justicia: en todas las noticias analizadas se verá el papel social y el impulso del cronista en plasmar y en ponerlo vista al público, para reflexión del lector sobre el protagonismo que obra la justicia en casos de especial impacto. En estos casos también se verá la posible influencia de los medios en decisiones judiciales, es decir, la presión social que ejerce la prensa los mass media, en casos especialmente mediáticos y que su repercusión social pueda interferir en la decisión del juez e incluso en las investigaciones policiales.

Las fuentes:

- Libros y artículos sobre historia de la prensa.

- Recopilación de artículos de hemeroteca de cada uno de los casos particulares que se citan a continuación y que corresponden a cada una de las etapas en las que se enmarca el trabajo (Para organizar el estudio de la crónica de sucesos se han definido 3 etapas históricas que pretenden estructurar de una forma definida no sólo la crónica en el ámbito periodístico sino su integración en un contexto histórico particular).

\section{- Siglo XXI: casos: NanySex, Marta del Castillo y Wikileaks}

El análisis de los datos se apoyará en la teoría de Hodge y Kress (1993), según la cual los procesos sociales convergen y se revelan en las formas lingüísticas de múltiples maneras.

El productor de un discurso, en tal sentido, necesita contar con una serie de recursos para la consecución de tales objetivos, para que su texto adquiera la forma correcta y cause el efecto buscado en la instancia de su recepción. Todo sujeto que hace uso del lenguaje persigue un fin con lo que expresa, y por ello es de suma relevancia que halle el modo adecuado de concretarlo.

Van Dijk (1997) cataloga el análisis de los textos periodísticos según:

- Cómo se presenta. Es decir, las elecciones de portada, tamaño y tono de los titulares, cómo se aplican las variaciones en la tipografía-tipo de fuente, uso o no de negritas, etc.-la inclusión o no de fotografías y el carácter de las mismas, así como otras variables en la presentación de una noticia constituyen motores semánticos que se erigen como formadores de modelos para el lector. De este modo se otorga prioridad y jerarquía a determinados actores o participantes sobre otros.

- La elección de estilo. Esta dimensión atiende al modo en que se organizan las categorías sintácticas, cómo se estructuran las oraciones, y, en definitiva, cómo a través de este recurso se hace énfasis en determinados hechos o actores.

- Estrategias semánticas. Este punto refiere a los aspectos del significado, el sentido o la interpretación del significado de un determinado elemento, símbolo, palabra, expresión o representación. La estrategia semántica comprende, así, aquello que se omite en un discurso, la dimensión latente del mismo. Aquello que se 
presupone en un discurso desempeña un papel decisivo en la interpretación y la constitución de la coherencia. Los presupuestos dependen del capital cognoscitivo y el conjunto de creencias y valores representados en las actitudes y modelos del lector.

- El estilo indirecto. Estilo y semántica se combinan dando como resultado un complejo conjunto de elementos que el periodista pone en acción de manera más o menos explícita para indicar coincidencia, complicidad, distancia, crítica u otra consideración sobre el contenido y los participantes del discurso.

- Retórica periodística. Si bien una función central del discurso periodístico es la de informar, es ineludible la cuestión retórica en todo objeto textual... En el caso de la crónica, estilo periodístico que comparte aspectos con la literatura, a los recursos de veracidad, el cronista agrega su visión y su modo de relatar el suceso, colocándose en una posición más o menos personal. Este aspecto, como veremos en el Estudio de Casos, se transformó a lo largo del tiempo.

- Condiciones de Recepción. Refiere este punto a los aspectos relacionados con la interpretación, comprensión y reflexión de los destinatarios frente al discurso periodístico.

Tres son las categorías que se aportan para la conformación del contexto: escenario, acción y participantes. En el escenario encontramos las variables espacio-temporales determinantes del contexto. En la acción encontramos que el discurso no es sólo forma y sentido sino que en él se desarrollan acciones sociales - por ejemplo defender o atacar a las instituciones, representar a un sector de la población, etc.- Por último, encontramos la variable de los participantes que para Van Dijk es central. Dentro de los participantes hallamos las variantes de: "comunicativos", participantes encargados de la producción del discurso; "interactivos" o aquellos participantes con los que el discurso se relaciona por algún motivo y que son definidos por su rol destinatarios, aliados, oponentes, etc.-; y por último los "sociales o políticos", participantes definidos por las condiciones de género, edad, profesión de cada actor interviniente.

Los medios de entre los cuales se recogió la información son variados ya que en algunos casos no coexisten en todas las épocas. Es significativo también el cambio de formatos de la prensa escrita de un período al otro: mientras que en las crónicas relevadas para el siglo XIX no aparecen imágenes ni tipografía a color, en el siglo XX comienzan a aparecer, y el siglo XXI agrega a la evolución del diseño gráfico el hipertexto y el refuerzo de la interactividad.

De acuerdo con el material relevado hemos establecido una serie de ejes de observación para encarar el análisis de los textos y contexto:

- Un primer eje atiende a cómo se caracteriza desde el texto periodístico a los participantes del discurso, en este caso, el criminal, la justicia, el pueblo, la prensa misma.

- Un segundo eje atiende al modo en que el contexto histórico es enunciado en el discurso periodístico.

\section{MUESTRA}

\subsection{El caso del 'Sacamantecas' o los genes del monstruo}

El caso Sacamantecas refiere a una serie de asesinatos de mujeres acontecidos en la pequeña comarca de Vitoria en la década de 1870, perpetrados por Juan Garayo, con tentativas de ser apresado en algunas oportunidades antes de su apresamiento definitivo. Juan Garayo recibió de la voz popular el alias de "Sacamantecas" debido a las brutales características de sus crímenes, cuyo antecedente ficcional podemos encontrar en los asesinos protagonistas de la novela policial y en los personajes de terroríficos mitos.

Las crónicas de sucesos, que ganaban terreno por primera vez en la prensa española del siglo XIX, tuvieron con este caso un prolífero material, ya que lejos de ser un hecho aislado se trató de una serie de crímenes prolongados en el tiempo que esparcieron el miedo en la población afectada.

Nos situamos en un momento histórico en que aún predomina un paradigma racionalista en las ciencias. La fe en el progreso de la humanidad sobre la base del avance científico era en la sociedad decimonónica una 
promesa que se concretaba a cada nuevo descubrimiento.

Es precisamente en los años en que se llevaron a cabo los crímenes del Sacamantecas en que la Criminología comenzaba su trayectoria científica gracias a los estudios de Cesare Lombroso en 1870 acerca de los rasgos físicos de los criminales que luego se plasmó en una obra de gran trascendencia, El Hombre Delincuente, en 1876 (Aller Maisonnave, 2010).

Aller Maisonnave, $(2010$, p.5) realiza en su trabajo sobre la historia de la criminología una distinción entre el paradigma clásico y el positivista, dos corrientes imperantes en el Derecho del siglo XIX. Al respecto señala:

"El paradigma de los clásicos era la responsabilidad del hombre libre, mientras que el de los positivistas fue la determinación del hombre al delito (...) mientras los clásicos dijeron al hombre observa el Derecho, los positivistas le dijeron al Derecho observa al hombre."

Una constante en las crónicas relevadas para este caso ha sido la aparición en el discurso periodístico del lenguaje médico y criminológico, que pone su atención en los rasgos físicos y psíquicos del criminal, aquellos que en teoría brindarían una explicación de su propensión al delito.

En algunos casos, desde los titulares se señala ya esta tendencia, como por ejemplo en la crónica de La Vanguardia, titulado "Autopsia de Garayo (a) Sacamantecas" (Escuder, 1881, p. 71).

"El criminal ha dejado de serlo; el cadáver ha resuelto el problema; su cerebro abierto ha manifestado la causa del crimen; su encéfalo ha sido una revelación. Sobre el mármol del anfiteatro, de entre los átomos, se levanta muda una protesta y también una lección".

\subsection{Jarabo, El Lute y el Proceso de Burgos. Tres historias criminales en varios actos}

\subsubsection{Caso Asesinatos de Jarabo}

José María Jarabo fue encontrado culpable del asesinato de cuatro personas en Madrid, en julio de 1958: el matrimonio de María de los Desamparados Alonso Bravo y Emilio Fernández Díaz, y su empleada doméstica Paulina Ramos en su domicilio y el comerciante Félix López Robledo, en su tienda. Fue detenido pocos días después, en medio de un gran despliegue policial, cuando iba a recoger un traje manchado de sangre a una tintorería. Tras la confesión, fue sentenciado a la pena de muerte y ejecutado en 1959.

Camarero, Julio. "Ha sido detenido el autor de los cuatro asesinatos descubiertos ayer". Pueblo. Crónicas Especiales. 22/07/1958. Madrid, Año XIX, N5874. Bajada: "Se trata de un chantajista y contrabandista de drogas llamado José Jarabo Pérez-Morris. Éxito de la policía española”. Incluye foto de una de las víctimas.

S/A. "José María Manuel Jarabo Pérez Morris, condenado a cuatro penas de muerte. Más las accesorias, pago de costas y 200.000 pesetas de indemnización a los herederos de cada una de las víctimas." Bajada: "Madrid. Jarabo ha sido condenado a cuatro penas de muerte por la Sección $\vee$ de nuestra audiencia Provincial, según sentencia hecha pública esta mañana, en medio de gran expectación." Incluye foto de José María Jarabo.

S/A "El asesino psicópata". Bajada: "José María Jarabo: autor de cuatro muertes fue el último ejecutado con garrote vil por la jurisdicción ordinaria”. Sumario del Crimen. Viaje a lo más profundo del delito.

González Deleito, Nicolás. “Jarabo, en el banquillo”. Impresiones del Proceso del Siglo.

S/A. "Los móviles del cuádruple asesinato en Madrid no han sido esclarecidos." ABC.24/07/1958 Edición de Andalucía, p. 12. Bajada. "Su autor se resiste a prestar declaración. Han sido detenidos muchos supuestos complicados en sus ilícitas actividades."

En cuanto al tono del escrito, nos encontramos frente a un relato que exalta el misterio del caso, buscando captar el interés del lector. Se señala al hecho como desconcertante y siniestro, capaz de sorprender hasta al más experto cronista:

"Hacía muchos años- el reportero lleva más de cuarto de siglo trabajando en la crónica de sucesos y no lo 
recuerda- que en Madrid no se perpetraba un drama de perfiles tan desconcertantes, de ángulos tan extensos y siniestros, como el que tiene movilizada a toda la Policía madrileña desde las primeras horas de la tarde del pasado lunes" (EI Caso, p. 2)

\subsection{2. 'El Lute'}

La Vanguardia ha dedicado varias páginas a la crónica sobre el criminal prófugo de la justicia. Por ejemplo, el 7 de junio de 1966 publicó una crónica titulada: "Gran redada de la Guardia Civil para localizar al quinqui 'El Lute'.En su bajada apunta: "A los cuatro días de su espectacular fuga del tren, aún no se sabe sobre su paradero".

El texto destaca la labor de las fuerzas de la Guardia Civil, a la cual denomina como "la Benemérita" en varias ocasiones, en la búsqueda del prófugo que adjetiva como exhaustiva.

A su vez, la referencia al criminal lo coloca como un individuo joven y peligroso:

Ejemplo 1: "'El Lute'es un elemento peligroso, tiene 24 años, y no dudaría en matar si se viese acorralad o" (La Vanguardia, 07/06/1966, p.11)

Ejemplo 2: "En fuentes autorizadas ajenas a la Benemérita, se pone de relieve que la peligrosidad de estos individuos hace anacrónica ya 'la cuerda de presos' que estos delincuentes incluso provocan haciéndose trasladar a otros lugares confesándose ellos mismos autores de delitos ajenos, con el fin de ocupar ocasión propicia de escapar.."

Sus actos son catalogados de espectaculares, colocando al lector en un terreno rayano a la ficción cinematográfica. El texto no deja de evocar lugares comunes de las historias de prófugos recogidas por la novela policial y los westerns cinematográficos. La elucubración del plan de escape desde la prisión, la fuga espectacular, la trashumancia del criminal malherido, etc.

El suceso en que se vio envuelto Eleuterio Sánchez en 1966 mereció la portada del Semanario de Sucesos. El 16 de junio de 1966 aparecía en las páginas de El Caso una crónica relatada en varias páginas bajo el titular “En Salamanca. El 'Quinqui Lute' fue capturado”. La portada destaca la foto ya difundida por La vanguardia, de 'El Lute' siendo escoltado por la guardia civil. Se destaca en otra tipografía en rojo la palabra "capturado".

En la edición del 23 de enero de 1971, bajo el título "La mujer de 'El Lute”" resaltado con mayor tamaño de tipografía en color rojo, El Caso desarrolla más detalles del suceso. El epígrafe agrega: "Ha desaparecido de su domicilio de Madrid".

En la portada de su edición del 9 de enero de 1971, El Caso exhibe como titular: " Tres fotografías de 'El Lute'. Se escapó." como era habitual, el Semanario de Sucesos incluyó en su relato del caso una serie de imágenes ilustrativas de los diferentes escenarios relacionados con el crimen por el cual el delincuente fue procesado, una de ellas la de la relojería donde, tras un intento de robo, 'El Lute' asesinó a un guardia de un balazo. Asimismo aparecen retratos del criminal, que por esas horas estaba siendo buscado sin éxito. Este tipo de fotografías difundidas en la prensa fueron las que permitieron a la gente de diversas localidades españolas efectuar reconocimientos, en la gran mayoría de los casos, fallidas, del prófugo.

Otras publicaciones de tirada nacional como $A B C$, Ya,..., dedicaran titulares a uno de los prófugos más famosos.

\subsubsection{Caso Proceso de Burgos}

Se denominó Proceso de Burgos al juicio a dieciséis miembros de la organización E.T.A. por el cargo de asesinato de tres personas y otros hechos delictivos, iniciado el 3 de diciembre de 1970 en la sede del Gobierno Militar en Burgos. El resultado parcial fue el dictamen de pena de muerte a varios miembros de la organización, pena que luego fue anulada y cambiada por la de cadena perpetua. La repercusión del suceso se vio exaltada por otro relacionado: el secuestro de un cónsul alemán por parte de E.T.A. en respuesta a dicho proceso, durante los días en que este tuvo lugar. Ambos hechos mantuvieron a la prensa española ocupada durante al 
menos gran parte del mes de diciembre de 1970.

Debido al estricto control que el régimen militar imperante en aquellos años hacía sobre la prensa, en líneas generales se expresa acuerdo con la opinión oficial. No obstante, los modos de enunciar a los participantes principales del discurso no serán los mismos en toda la prensa escrita.

Un seguimiento de las portadas de El Alcázar nos permite situar el posicionamiento de su discurso periodístico, claramente a favor del régimen nacionalista. En estas páginas, Franco aparece como una figura positiva, garante del orden público y de una deseada unidad nacional, mientras que la organización E.T.A. es enunciada de manera tajantemente negativa como "terrorista" "separatista" "organización vasca separatista", "insubordinados", etc.

En las publicaciones de Pueblo encontramos un tono menos parcial respecto de los implicados en el caso. El discurso periodístico se muestra más neutro respecto del apoyo al régimen. Por ejemplo, E.T.A. se enuncia como una organización "activista" y "clandestina" en lugar de "separatista" y "terrorista".

\subsection{De hackers y nuevas categorías criminales. Periodismo y Derecho en la contemporaneidad}

Es un lugar común señalar que la contemporaneidad ofrece al investigador social un panorama complejo y en constante transformación. Sin embargo es una afirmación que continúa siendo acertada a la luz de la incertidumbre que producen ciertos fenómenos de la vida social contemporánea, que provocan la necesidad de generar nuevas categorías para su abordaje. Anteriormente desarrollamos un esbozo de las transformaciones en el campo de la comunicación de masas debido a los efectos de la globalización y al nacimiento de nuevos paradigmas comunicacionales alentados por el surgimiento de Internet. Para abordar el análisis de casos del siglo XXI, necesitamos también apuntar que existe un panorama de transformación en el Derecho, campo que se vuelve una temática frecuente en los discursos periodísticos contemporáneos. Es que, desde, aproximadamente, fines del siglo XX, las legislaciones penales de gran parte de los países de Occidente están sufriendo un conjunto de transformaciones a un ritmo vertiginoso y sobre la base de principios muy profundos. Precisamente esta necesidad de redefinición de los principios base del Derecho Penal es lo que la sociedad contemporánea demanda de la justicia, una demanda muchas veces canalizada por el discurso de los medios de comunicación. Lejos de ser una respuesta omnipotente ante el delito, fuerza restauradora del orden en la que el pueblo depositaba su fe, como lo fuera el Derecho durante la modernidad, la sociedad contemporánea manifiesta frecuentemente su desencanto respecto de las instituciones jurídicas y del discurso jurídico.

\subsubsection{Caso Nanysex}

En 2008 fue descubierta una red de pederastia que actuaba en Madrid y Murcia, y difundía su material a través de Internet. El principal acusado es Álvaro I.G. alias Nanysex, además de al menos tres implicados más. La gran repercusión del caso se debió por un lado a la alarma social desatada por la existencia de esta clase de criminales, y por otro, al proceder de la justicia al examinar el caso y dictar sentencia en una primera instancia, rebajando luego la condena tras realizar revisiones técnicas.

La Vanguardia publicó sobre la sentencia el 21 de julio de 2008 bajo el titular: "Pena de 58 años de cárcel a 'Nanysex' por once delitos de abuso sexual y corrupción de menores" una nota donde se detallan los cargos levantados contra el pederasta Álvaro I.G. alias Nanysex y sus cómplices. El texto describe en términos jurídicos de qué se acusa a los procesados, sin incluir una apreciación directa sobre dicha sentencia

Diferente es la apreciación de ABC sobre la sentencia, que en una nota titulada "«Nanysex», condenado a 58 años porque para los jueces sólo cometió abusos sexuales" (22/07/2008). Desde el titular se manifiesta el descontento del periodista con la sentencia.

El País publicó bajo el titular: “El Supremo reduce en 24 años las penas a los pederastas del caso 'Nanysex'”, el 29 de octubre de 2009. En la bajada relata: "El tribunal reduce de 58 años a 44 años y medio la pena de prisión para el pederasta, que abusó de cinco niños.- La sala argumenta que se aplicó de forma indebida la agravante de abuso de confianza" 
El Heraldo también publicó sobre la sentencia aplicada a la red de pederastas, bajo el titular: "La Audiencia de Madrid rebaja la condena a 'Nanysex' al no ver delito de violación." En el texto predominan las apreciaciones del abogado de las víctimas y el Ministerio Fiscal sobre la actuación del tribunal.

\subsubsection{Caso Wikileaks}

En 2010 una serie de documentos secretos pertenecientes al ejército de Estados Unidos salió a la luz a través de la plataforma Wikileaks. Su creador, Julián Assange es desde entonces una figura pública que continúa su labor de filtración de documentos, primero desde su asilo en la embajada ecuatoriana y luego desde su prisión domiciliaria en Inglaterra. Fue buscado por Interpol, arrestado y absuelto por sus presuntos delitos informáticos, aunque Estados Unidos nunca dejó de prestar atención a sus actividades. Assange también es solicitado por la justicia sueca acusándosele de cometer delitos sexuales en tal país. Si Assange es un hacker que busca la fama o periodista que busca la verdad, es el eje del debate mediático. La otra cara del caso es el soldado estadounidense Bradley Manning, quien es acusado de haber colaborado con Wikileaks filtrando documentos confidenciales y desde entonces se halla en prisión. El 20 de diciembre de 2012, La vanguardia publicaba en su edición digital una crónica actualizando las actividades programadas por Julián Assange, creador de la controvertida plataforma Wikileaks que le valió la persecución de la justicia de EEUU e incluso su pedido de captura por Interpol. Por otro lado, Assange fue acusado de cometer delitos sexuales en Suecia, país que le niega el asilo .Bajo el título: "El hacker comparece por segunda vez desde su encierro en la embajada de Ecuador y afirma que su trabajo no se verá <>" Se incluye una fotografía de Assange, que, como en la mayoría de las aparecidas en la prensa, lo muestra despreocupado y sonriente.

En una crónica publicada en la edición digital de ABC, el 30 de noviembre de 2012, se retoma también el relato del soldado en prisión bajo el titular: "«Pensé que iba a morir en una celda», relata el soldado, que lleva más de dos años en prisión." A través de las palabras de David Coombs, abogado defensor de Manning, el periodista describe las condiciones de la reclusión resaltando en negritas algunos aspectos:

"ha relatado este jueves durante la última audiencia previa al juicio el trauma que ha sufrido a manos de soldados estadounidenses durante su encarcelamiento" (ABC, 30/11/2012)

El Mundo, es uno de los pocos medios que hace mención del contenido de los documentos propagados en teoría a través de Manningen Wikileaks:

"El soldado Bradley Manning se ha declarado culpable en el consejo de guerra de acceder, guardar y filtrar documentos secretos a Wikileaks, incluyendo correos electrónicos y el famoso vídeo en el que se ve a un helicóptero estadounidense tirotear a un grupo de iraquíes en Bagdad y causar la muerte de dos periodistas de la agencia de noticias Reuters cuya cámara es confundida con un lanzagranadas por los tripulantes". (Pardo, 29/11/2012)

Hasta el momento, en La Vanguardia y ABC, sólo se había referido a tales documentos como "confidenciales" o "secretos".

El País, por su parte, publicó varias notas sobre el afamado caso. El 21 de diciembre, con ocasión de la aparición pública de Assange escribió bajo el titular: "Assange recuerda al mundo que sigue vivo y anuncia nuevas filtraciones." Una nota que en su bajada apunta: "El fundador de Wikileaks afirma que este año verán la luz más de un millón de documentos que afectan "a cada país del mundo". La referencia a su actividad como a la de un "hacker" es nula, simplemente se lo señala como fundador de la plataforma.

\subsubsection{Caso Marta del Castillo}

La desaparición y el presunto asesinato de la joven Marta del Castillo Casanueva en Sevilla en enero de 2009, ha despertado el interés de la sociedad y medios de comunicación españoles. El suceso se vio marcado por una serie de cambios en las versiones de los hechos de los acusados, que guiaron el accionar de las fuerzas policiales hacia diferentes lugares con el fin de hallar el cuerpo, que hasta el día de hoy no fue encontrado.

El principal acusado, quien confesó ser el asesino de la joven, es Miguel Carcaño, quien fue procesado y 
condenado. El resto de los presuntos implicados se encuentran en libertad luego de ser juzgados. Entre los acusados absueltos se encuentran dos amigos del asesino confeso, uno de ellos menor de edad y en libertad condicional se hallan el hermanastro de Carcaño y su novia. Se presume que el menor de edad, Francisco Javier García Marín alias "El Cuco" participó como autor material del crimen junto con Carcaño, mientras que los otros tres fueron acusados de haber sido cómplices en el ocultamiento del cuerpo.

El caso Marta del Castillo está marcado por la crítica al accionar de la justicia, la cual derivó en manifestaciones populares, en ocasiones recogidas por la prensa. Tal fue la repercusión del hecho en los medios, que el decano del Colegio de Abogados solicitó al periodismo la mesura sobre sus palabras respecto de la sentencia en pos de preservar la imagen de la justicia:

"José Joaquín Gallardo, ha mencionado que es una grave irresponsabilidad que gran parte de la opinión pública y muchos medios de comunicación estén valorando de forma agresiva, sesgada e irreflexiva la sentencia llevada a cabo en el caso de Marta Del Castillo. En declaraciones realizadas a Efe, Gallardo lamentaba y se mostraba apenado por el hecho de que los comentarios vertidos sobre esta sentencia están menoscabando injustamente el prestigio de la justicia y continuaba "la avalancha de valoraciones peyorativas crea una situación que atenta injustificadamente contra la honorabilidad de nuestra justicia". (González Garmendia, 15 de enero de 2012)

El comentario del decano muestra por un lado la magnitud que puede alcanzar la repercusión de un suceso en los medios masivos de comunicación y a su vez el poder que estos reportan, que llaga al punto de incluir sobre la imagen pública de la justicia.

Como en los otros casos relevados para esta etapa, y como ocurre desde que la crónica de sucesos ha alcanzado aceptación social hay dos cuestiones principales que emergen cuando un suceso alcanza gran repercusión: una es la demanda del periodista profesional de mantener informado al ciudadano, aspecto que reposa sobre la base de la libertad de prensa -es decir, la capacidad de recoger y exponer información verídica de fuentes gubernamentales periodísticas $u$ otras propias de la profesión a fin de que se asegure el derecho a la información de los ciudadanos -y otra es la del afán de lucro de los medios masivos de comunicación, que con su mediatización del crimen pueden alcanzar grandes éxitos en ventas y publicidad. Los límites entre una y otra postura permanecen a menudo permeables.

\section{CONCLUSIONES}

Hemos visto en estas páginas cómo la crónica construye en cada momento sus destinatarios, y los diversos participantes de sus discursos. Así mismo hemos atendido a la manera en que la crónica hace uso del lenguaje, con la finalidad de configurar un relato que agregue interés a los sucesos de actualidad y encauce el espectro de opiniones posibles sobre estos. Esta característica nos habla de un innegable poder, que la comunicación periodística en general posee, que es el de configurar, moldear y difundir, desde una voz profesional, los relatos que circulan en un momento dado, una vez recogida la información o documentación verídica que ha de ser su fundamento.

La intencionalidad del emisor del discurso, el cronista en este caso, será más o menos clara según el caso, y dependerá del lugar al que desee conducir la mirada lectora. Los medios de comunicación de masas constituyen la principal fuente de las definiciones sociales y políticas que circulan en una comunidad, produciendo efectos ideológicos porque la estructura latente de los mensajes se perpetúa en las subsiguientes generaciones. Las crónicas de sucesos del siglo XIX, que hemos abordado a través del análisis de los discursos aparecidos en la prensa sobre los crímenes en serie del "Sacamantecas" nos han llevado a un universo simbólico atravesado por el discurso de la ciencia, en un momento en que conformaba tanto la crónica de sucesos como género dentro del periodismo español como la criminología en tanto disciplina del conocimiento. Desde estos relatos hemos visto cómo se configuró en la prensa una imagen del criminal: aquel desviado psíquica y moralmente de las normas sociales, aquel señalado bien como un "monstruo" o como un loco. El rol de la justicia, o de las fuerzas del orden, se ve opacado por otros participantes destacados, a saber, médicos y peritos forenses, capaces de brindar las respuestas a los citados interrogantes. No obstante, cuando la justicia o a la Guardia Civil es referenciada en los discursos de la prensa se la reviste de credibilidad y eficacia. El siglo 
$\mathrm{XX}$ emerge como un momento de crisis social, marcado fuertemente por el refuerzo de los totalitarismos en el terreno político. Hemos visto cómo por un lado se han sistematizado los procesos de control de la prensa escrita durante el franquismo y cómo se han reforzado los aspectos lucrativos del periodismo en esta etapa. Esto marca dos aspectos fundamentales de la crónica de sucesos: una es la de la monopolización de los discursos políticos y sociales a través de la prensa por parte de las fuerzas militares en el poder, y otra es la escalada del sensacionalismo y el amarillismo en la prensa con fines lucrativos. Esto derivó en la propagación tanto de publicaciones falangistas, como de publicaciones limitadas por el control del régimen, la suspensión de publicaciones, y la aparición de nuevas publicaciones que suscitaron gran interés popular, como por ejemplo el semanario El Caso. En las páginas de El Caso, como en otras crónicas de sucesos aparecidas en la prensa encontramos un efecto de dramatización de los hechos criminales, al punto de asemejarse a los relatos de ficción, como sucedió con "El Lute" y los crímenes de Jarabo. El relato espectacular de las fugas de "El Lute", como vimos, incluso fue llevado a la literatura y al cine. La descripción de los escapes del criminal, las tácticas de las fuerzas policiales para apresarlo, lleva al lector a un escenario de héroes y villanos casi cinematográfico. Por otro lado, también hallamos en el análisis de los documentos del período un caso que por su matriz política fue tratada por la prensa de una manera parcial y sin demasiados aditivos poéticos. El proceso de Burgos a través de las crónicas del siglo XX mostró la capacidad de los medios para configurar imágenes del poder y para absorber los discursos hegemónicos. También demostró la capacidad del lenguaje para construir representaciones acordes a los fines discursivos. Por último, el siglo XXI nos condujo a una etapa evolutiva del género en cuestión situada en medio de la crisis de los grandes relatos de la modernidad. Específicamente entra en juego el cuestionamiento a la justicia en sus aspectos técnicos y simbólicos. La aparición constante de nuevas situaciones y nuevos actores sociales o como hemos denominado "nuevas categorías criminales" en la sociedad contemporánea exige una revisión del derecho penal vigente. Los casos elegidos tienen en común por un lado su gran repercusión mediática, y por otro lado, la posibilidad de sentar jurisprudencia. La reforma del código penal acerca de los delitos informáticos, de la pederastia, de las redes delictivas a través de Internet, o bien en materia imputabilidad ha estado presente en los escenarios sociales reconstruidos en la prensa. La representación de una justicia ineficiente, o de una justicia incapaz de salirse de su tecnicismo ha sido el tópico común de los discursos sobre los procesos judiciales aparecidos en la prensa para cada uno de estos casos. Por otro lado, el caso Wikileaks también abre el debate sobre la libertad de expresión y la libertad de prensa, y sobre la propia deontología periodística. ¿Cómo se define el periodismo en una sociedad comunicada en red, global y plural? ¿Cuál es el periodismo "verdadero"? son cuestiones que emergen de las crónicas sobre el caso Wikileaks y su principal implicado Julián Assange, que tanto puede ser para el cronista un "activista", un defensor de la verdad, como un "hacker" un "experiodista" o un oportunista. Nos encontramos, pues, frente a un género periodístico poblado de matices que ejerce influencia en los modos de entender el mundo en cada momento histórico y que, a su vez, puede funcionar como documento para el estudio de la historia, ya que en sus líneas encontramos extractos del universo simbólico de una época. En tal sentido, podemos decir que ningún periodista escapa a su tiempo, y a su vez todo periodista es capaz de transformar su tiempo.

\section{REFERENCIAS BIBLIOGRÁFICAS}

DE FLEUR, M. (1970). Teorías de la Comunicación Masiva. Buenos Aires, Argentina: Paidós.

DURKHEIM, É. (2012). Las reglas del método sociológico y otros escritos. Madrid: Alianza.

GUTIÉRREZ ESPADA, L. (1982). Historia de los Medios Audiovisuales. 1 (1838-1926) (Vol. 1). Madrid, España: Ediciones Pirámide.

HERRERO, J. C. (2009). Manual de Teoría de la Información y de la Comunicación. (J. C. Herrero, Ed.) Madrid, España: Universitas.

IMBERT, G. (2000). La tentación del suicidio. Representaciones de la violencia e imaginarios de muerte en la cultura de la postmodernidad. Barcelona: Paidós.

MONZÓN, C. (1987). La opinión pública. Teorías, concepto y métodos. Madrid: Tecnos.

QUESADA, M. (2007). Periodismo de Sucesos . Madrid: Síntesis. 
REY, G. (2000). www.library.fes.de. Recuperado el 07 de 01 de 2013, de http://library.fes.de/pdf-files/bueros/c3comunicacion/07327.pdf

REY, G. (s.f.). www.library.fes.de. Recuperado el 07 de 01 de 2013, de http://library.fes.de/pdf-files/bueros/c3comunicacion/07327.pdf

VICO, E. A. (2006). Violencia y Medios: Distorsiones y Adicción. En V.V.A.A., Violencia Desenfocada. Sevilla: Padilla Libreros.

\section{Breve semblanza de los autores}

Alberto Albacete Carreño es doctor por la UCJC, Máster Universitario en Gestión de la Seguridad, Crisis y Emergencias URCJ. Licenciado en Criminología y en Derecho UCJC. Jefe de Policía Local de Valdemoro.

María Pilar Antolínez Merchán es doctora por la UCM, licenciada en Sociología y Ciencias Políticas UCM. Vicedecana del llustre Colegio de Doctores y Licenciados en Ciencias Políticas y Sociología. Profesora Facultad Ciencias de la Comunicación y Departamento de Criminología.

M $^{\text {a }}$ Cristina Cañamero Alvarado es doctora por la UCJC, licenciada en Historia por la UAM. Profesora en la Facultad de Ciencias de la Comunicación UCJC, especialista en Historia de los Medios.

(1) Palabra inglesa "almohadilla" y "etiqueta", los usuarios lo utilizan encadenando palabras para dar importancia a un tema, cuando es citado por más usuarios dependiendo del número se convierte en uno de los temas principales para seguir en la red social.

Ámbitos. Revista Internacional de Comunicación, n.26, año 2014, tercer trimestre (otoño). 